\title{
Noneosinophilic asthma in children: relation with airway remodelling
}

\author{
S. Baraldo*, G. Turato*, E. Bazzan*, A. Ballarin*, M. Damin*, E. Balestro*, K. Lokar \\ Oliani*, F. Calabrese $^{\#}$, P. Maestrelli ${ }^{\mp}$, D. Snijders ${ }^{+}$, A. Barbato ${ }^{+}$and M. Saetta*
}

ABSTRACT: Noneosinophilic asthma is increasingly recognised as an important clinicalpathological phenotype in adults. However, this entity has scarcely been investigated in children. In particular, it is unknown whether airway remodelling would develop in children with noneosinophilic asthma to the same degree as in children with eosinophilic disease.

We analysed bronchial biopsies from 80 children undergoing bronchoscopy for appropriate clinical indications: 21 with noneosinophilic asthma, 34 with eosinophilic asthma and 25 control children. Features of airway remodelling - basement membrane thickening, epithelial loss and angiogenesis - and immune activation - inflammatory infiltrate, interleukin (IL)-4, IL-5, transforming growth factor (TGF)- $\beta$, TGF- $\beta$ receptor type II - were quantified by histology and immunohistochemistry.

The main components of airway remodelling were present in children with noneosinophilic asthma just as in those with eosinophilic disease. Indeed, compared with control children, both noneosinophilic and eosinophilic asthmatic children had thickened basement membrane, increased epithelial loss and higher number of vessels. Moreover, in both groups of asthmatics, expression of IL-4 and IL-5 was increased, while that of TGF- $\beta$ receptor type II was reduced, compared with controls.

This study demonstrates that structural changes typical of asthma develop in asthmatic children even in the absence of a prominent eosinophilic infiltrate, indicating that other mechanisms, besides eosinophilic inflammation, may promote airway remodelling early in life.

KEYWORDS: Angiogenesis, basement membrane thickening, eosinophilia, epithelial damage, paediatric asthma

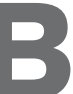
ronchial asthma has become an increasing public health concern, especially in industrialised countries. The prevalence of asthma has increased significantly over the past $20 \mathrm{yrs}$ and its incidence has become particularly high in children [1, 2]. It is now widely accepted that childhood asthma is more complex than previously recognised, with distinct phenotypes that may differ significantly in terms of aetiology, pathophysiology and clinical outcomes [3-5].

Eosinophils have long been credited with a central role in asthma. Indeed, the pathology of asthma is characterised by a chronic inflammation of the airways, comprising increased numbers of eosinophils, mast cells and T-lymphocytes. This proinflammatory milieu is modulated via T-helper (Th)2 mechanisms (involving interleukin (IL)-4 and IL-5), but recent evidence suggests that other subsets of lymphocytes may be important, such as Th17 and Th9, whose activation depends on transforming growth factor (TGF)- $\beta$ signalling [6]. Furthermore, the inflammatory reaction is associated with structural changes of the bronchial wall. These changes, collectively termed "airway remodelling", include epithelial loss, basement membrane thickening, smooth muscle increase and angiogenesis.

The relationship between eosinophilic inflammation and airway remodelling is not completely understood; traditionally, remodelling has been considered the unavoidable consequence of longterm airway inflammation. However, the first studies that evaluated the pathology of asthma in children showed that both airway eosinophilia and all the structural changes characteristic of asthma were present in children, even at preschool age [7-11]. These results indicate that the

\section{AFFILIATIONS}

*Dept of Cardiac, Thoracic and Vascular Sciences, University of Padua and Padua City Hospital ${ }^{\text {\#} D e p t ~ o f ~ M e d i c a l ~ D i a g n o s t i c ~}$ Sciences and Special Therapies University of Padua,

"Dept of Environmental Medicine and Public Health, University of Padua and

+Dept of Paediatrics, University of Padua, Padua, Italy.

CORRESPONDENCE M. Saetta

Università degli Studi di Padova Dipartimento di Scienze Cardiologiche

Toraciche e Vascolari Unità Operativa di Pneumologia Via Giustiniani 3 35128 Padova Italy E-mail: marina.saetta@unipd.it

Received: Oct 282010 Accepted after revision: Jan 252011

First published online: Feb 102011 
processes leading to remodelling of the airway wall begin early in the course of the disease and most probably occur in parallel with the establishment of chronic inflammation rather than subsequently to it.

Moreover, most studies that have provided direct evidence for eosinophils as effectors of tissue remodelling were performed in animal models [12, 13]. Evidence that eosinophils are required for development of airway remodelling is less compelling in humans and, more importantly, it is now well established that human asthma does not necessarily imply eosinophilic inflammation. Indeed, although asthmatics have median eosinophil counts higher than controls, a significant proportion of patients shows no evidence of eosinophilia, despite having all symptoms and functional alterations typical of asthma [14-16].

The issue of noneosinophilic asthma was first raised in patients with severe disease [17], but there is now more comprehensive information, using induced sputum, that the noneosinophilic phenotype is rather common among patients with asthma, not only in those with severe, but also in those with milder forms of the disease [14-16].

As far as we know, it has never been investigated whether the eosinophilic and noneosinophilic patterns of inflammation are associated with different characteristics of airway remodelling in children. Hence, the aim of this study was to investigate the pattern of structural changes (epithelial loss, basement membrane thickening and angiogenesis) and cytokines (IL-4, IL-5, TGF- $\beta$ and its type II receptor) in children with noneosinophilic asthma, comparing the results to those of children with the eosinophilic form of the disease and control children without asthma.

\section{METHODS}

\section{Subjects}

80 children undergoing fibreoptic bronchoscopy for appropriate clinical indications were recruited in this study: 55 had symptoms of asthma, while 25 did not have these symptoms and were included as controls. Children were defined as having asthma when they had repeated episodes of wheezing, breathlessness and cough, particularly at night and early in the morning, that were present even when the child did not have a cold. Moreover, in all asthmatic children, symptoms had to be responsive to bronchodilators. Presence and reversibility of episodic symptoms were assessed by a specific questionnaire administered to parents investigating the pattern of symptoms and the clinical benefit of bronchodilators (symptom resolution or significant improvement). This information was confirmed by the child's paediatrician $[7,10]$.

Asthmatic children were then categorised as eosinophilic or noneosinophilic according to a threshold corresponding to the 90th percentile of the distribution of biopsy eosinophils in controls (28 cells $\cdot \mathrm{mm}^{-2}$; fig. 1). Based on this partitioning, in our population of asthmatic children, 34 had eosinophilic asthma (62\%) and 21 had noneosinophilic asthma (38\%).

Children with eosinophilic asthma underwent bronchoscopy for recurrent pneumonia $(n=19)$, chronic cough $(n=10)$, stridor $(n=1)$, difficult asthma $(n=3)$ or middle lobe syndrome $(n=1)$; children with noneosinophilic asthma underwent bronchoscopy

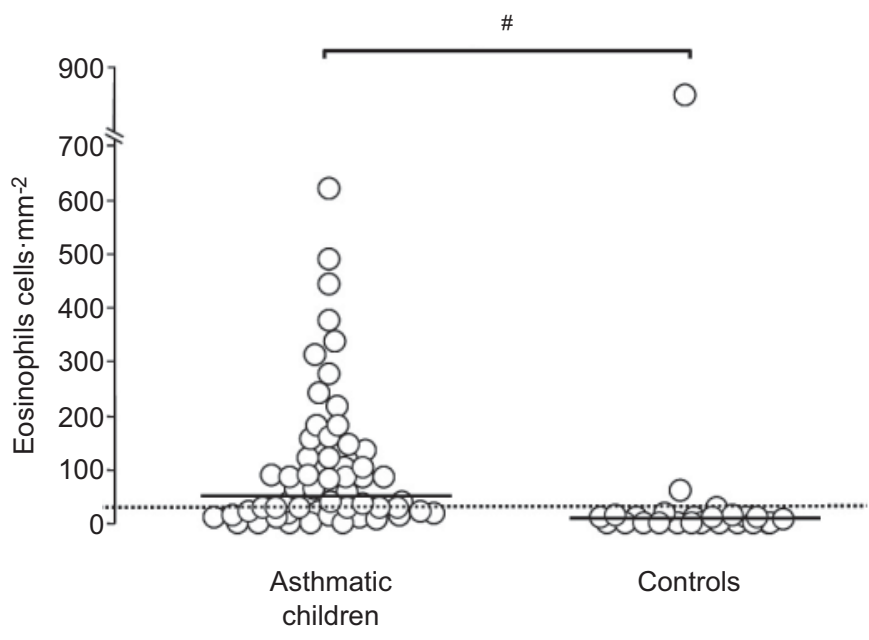

FIGURE 1. Individual values for eosinophils in bronchial biopsies in asthmatic and control children. __ : median values; ---------: $90^{\text {th }}$ percentile of eosinophil values in controls ( $28 \mathrm{cells} \cdot \mathrm{mm}^{-2}$ ), used to subgroup asthmatics as noneosinophilic and eosinophilic. ${ }^{*}: p<0.0001$.

for recurrent pneumonia $(n=11)$, chronic cough $(n=7)$, stridor $(n=1)$, difficult asthma $(n=1)$ or obstructive sleep apnoea syndrome $(\mathrm{n}=1)$ and control children underwent bronchoscopy for recurrent pneumonia $(n=12)$, chronic cough $(n=9)$, stridor $(n=3)$ or laryngomalacia $(n=1)$.

On the basis of the intensity of treatment required to control symptoms, children were considered to have mild, moderate or severe disease [1]. 36 out of 55 asthmatic children had mild asthma and were treated with inhaled salbutamol only when needed. 15 out of 55 asthmatic children had moderate asthma (treated with equivalent daily doses of beclomethasone ranging 200-400 $\mu \mathrm{g}$ ) and the remaining four out of $55 \mathrm{had}$ severe asthma (equivalent daily doses of beclomethasone $\geqslant 800 \mu \mathrm{g}$ ). None of the children were being treated with oral corticosteroids or antibiotics at the time of fibreoptic bronchoscopy. The distribution of mild, moderate and severe asthma was similar in the eosinophilic and noneosinophilic groups. In particular, mild asthma was present in 20 (59\%) out of 34 children with eosinophilic asthma and 12 (57\%) out of 21 children with noneosinophilic asthma. Moderate asthma was present in 11 (33\%) children with eosinophilic asthma and in eight $(38 \%)$ with noneosinophilic asthma. Severe asthma was present in three $(8 \%)$ children with eosinophilic asthma and in one $(5 \%)$ child with noneosinophilic asthma.

The presence of atopy was defined by an increase in total (paper radioimmunosorbent test) or specific (radioallergosorbent test) immunoglobulin (Ig)E. In particular, specific IgE for all the following aeroallergens were investigated in all children: house dust mite (Dermatophagoides pteronyssinus and Dermatophagoides farinae), moulds (Alternaria alternate), cat dander and grass pollens (Lolium perenne, Poa pratensis, Phleum pratense, Dactylis glomerata and Cynodon dactylon). Control children were nonatopic.

The prevalence of atopy was similar in children with eosinophilic and noneosinophilic asthma: 56\% of children 
with eosinophilic asthma and 52\% of those with noneosinophilic asthma were atopic.

All children underwent routine blood tests, while spirometry was performed only in children who were able to cooperate with the test $(n=39)$. Forced expiratory volume in $1 \mathrm{~s}(\mathrm{FEV} 1)$, forced vital capacity (FVC) and FEV1/FVC were measured using a 10-L bell spirometer (Biomedin, Padua, Italy) and the best of three manoeuvres was expressed as \% predicted reference values.

Bronchoscopy with airway biopsies and bronchoalveolar lavage was conducted according to guidelines [18] and written consent was obtained from the children's parents. The study was performed according to the Declaration of Helsinki and was approved by Padua Hospital Ethics Committee (Institutional Review Board approval number 494P). Some of the children examined in the present study had been included in a previous study [10].

\section{Biopsy analysis}

Bronchial biopsies were processed as described in the online supplementary material. Analysis of epithelial loss and reticular basement membrane thickness was performed on sections stained with haematoxylin-eosin. Briefly, epithelial loss was quantified by measuring the length of the incomplete epithelium and expressed as a percentage of the total basement membrane length. The thickness of the reticular basement membrane was assessed by taking measurements at $50-\mu \mathrm{m}$ intervals along all the basement membrane length. Vessels were assessed by immunohistochemistry using a monoclonal anti-CD31 antibody as previously described [8], and expressed as number of vessels per $\mathrm{mm}^{2}$ of examined subepithelium. Analysis of inflammatory cells (eosinophils, neutrophils, mast cells, macrophages, CD4- T-lymphocytes), as well as of IL-4, IL-5, TGF- $\beta$ and TGF- $\beta$ receptor type II was performed by immunohistochemistry as previously described [7, 8], and results were expressed as number of positive cells per $\mathrm{mm}^{2}$ of examined subepithelium.

The cases were coded and measurements performed without knowledge of the clinical data. Differences were evaluated using ANOVA and unpaired t-test for clinical data, while the nonparametric Kruskal-Wallis test and Mann-Whitney U-test were applied for morphological data.

Correlation coefficients were calculated using Spearman's rank method.

\section{RESULTS}

The bronchoscopy procedure was well tolerated by all children and no complications were encountered. The clinical characteristics of the children studied are shown in table 1. Children with eosinophilic asthma were slightly older than children with noneosinophilic asthma and controls. Importantly, the age at onset of symptoms and symptom duration were not significantly different between the two groups of asthmatics.

FEV1 (\% pred), FVC (\% pred) and FEV1/FVC did not differ significantly between children with eosinophilic and noneosinophilic asthma. The two groups of children also showed a similar degree of reversibility after bronchodilator administration. Levels of circulating eosinophils and BAL eosinophilic

\begin{tabular}{|c|c|c|c|}
\hline & Eosinophilic & Noneosinophilic & Control \\
\hline Subjects & 34 & 21 & 25 \\
\hline Males/females & $16 / 18$ & $14 / 7$ & $10 / 15$ \\
\hline Age yrs & $7.2 \pm 0.5^{+}$ & $5.0 \pm 0.5$ & $4.9 \pm 0.5$ \\
\hline FEV $_{1}^{\#} \%$ pred & $86.4 \pm 2.6^{\star \star}$ & $90.7 \pm 6.3$ & $101.6 \pm 2.5$ \\
\hline $\begin{array}{l}\Delta \mathrm{FEV} 1 \text { post- } \boldsymbol{\beta}_{2} \text {-agonist }{ }^{\top} \% \\
\text { baseline }\end{array}$ & $10 \pm 2.0$ & $11 \pm 3.0$ & \\
\hline FVC $^{\#} \%$ pred & $91.6 \pm 2.8$ & $91.7 \pm 5.7$ & $100.6 \pm 2.5$ \\
\hline $\mathrm{FEV}_{1} / \mathrm{FVC}^{\#} \%$ & $85.5 \pm 1.8$ & $88.1 \pm 2.8$ & $91.7 \pm 2.2$ \\
\hline $\begin{array}{l}\text { Age at onset of symptoms } \\
\text { yrs }\end{array}$ & $2.8 \pm 0.6$ & $2.2 \pm 0.4$ & \\
\hline Duration of symptoms yrs & $4.3 \pm 0.6$ & $2.7 \pm 0.5$ & \\
\hline $\begin{array}{l}\text { Blood eosinophils } \\
\text { cells } \cdot \mathrm{mm}^{-3}\end{array}$ & $412 \pm 63^{+}$ & $213 \pm 25$ & $179 \pm 20$ \\
\hline BAL ECP $\mu \mathrm{g} \cdot \mathrm{L}^{-1}$ & $71 \pm 14^{\star *}$ & $52 \pm 20$ & $16 \pm 5$ \\
\hline Atopy yes/no & $19 / 15$ & $11 / 10$ & $0 / 25$ \\
\hline ICS treatment yes/no & $11 / 23$ & $8 / 13$ & \\
\hline
\end{tabular}

Data are expressed as $n, n / n$ or mean \pm SEM. FEV 1 : forced expiratory volume in $1 \mathrm{~s}$; \% pred: \% predicted; FVC: forced vital capacity; BAL: bronchoalveolar lavage; ECP: eosinophilic cationic protein; ICS: inhaled corticosteroid. ${ }^{\#}$ : pulmonary function testing was performed in 23 children with eosinophilic asthma, seven children with noneosinophilic asthma and nine control children. ${ }^{`}: \Delta \mathrm{FEV} 1$ post- $\beta_{2}$-agonist was available in 20 children with eosinophilic asthma and five children with noneosinophilic asthma. ${ }^{+}: p \leqslant 0.05$ compared with children with noneosinophilic asthma and with control children; **: $p<0.01$ compared with control children

cationic protein were increased in eosinophilic asthmatic children, but not in noneosinophilic asthmatic children, compared with control children.

When we examined the different parameters of airway remodelling, we found that not only children with eosinophilic, but also those with noneosinophilic asthma, had a thickened basement membrane (median 5.4 (range 2.5-11.5) $\mu \mathrm{m}$ and 5.3 (3.8-8.6) $\mu \mathrm{m}$, respectively, versus 3.1 (1.8-4.9) $\mu \mathrm{m}$ for controls; $\mathrm{p}<0.0001$ versus controls for both), an increased epithelial loss (65 (18-100)\% and $50(12-94) \%$, respectively, versus $33(0-100) \%$ for controls; $\mathrm{p}<0.005$ and $\mathrm{p}<0.05$, respectively, versus controls) and an increased number of vessels (259 (9-704) vessels $\cdot \mathrm{mm}^{-2}$ and $250(0-493)$ vessels $\cdot \mathrm{mm}^{-2}$, respectively, versus $114(0-576)$ vessels $\cdot \mathrm{mm}^{-2}$ for controls; $\mathrm{p}<0.05$ versus controls for both) (fig. 2). Examples of these morphological changes in a child with noneosinophilic and a child with eosinophilic asthma are illustrated in figure 3.

Furthermore, both eosinophilic and noneosinophilic asthmatic children had increased numbers of IL-4-positive cells (156 (0676) cells $\cdot \mathrm{mm}^{-2}$ and $117(0-824)$ cells $\cdot \mathrm{mm}^{-2}$, respectively, versus 56 (8-732) cells $\cdot \mathrm{mm}^{-2}$ for controls; $\mathrm{p}<0.0001$ and $\mathrm{p}=0.007$, respectively, versus controls), as well as IL-5-positive cells (310 $(0-834)$ cells $\cdot \mathrm{mm}^{-2}$ and $356(0-920)$ cells $\cdot \mathrm{mm}^{-2}$ versus $235(0-$ 659 ) cells $\cdot \mathrm{mm}^{-2}$ for controls; $\mathrm{p}<0.05$ and $\mathrm{p}=0.007$, respectively, versus controls) (fig. 4). No significant difference in the expression of TGF- $\beta$ was observed among the three groups 

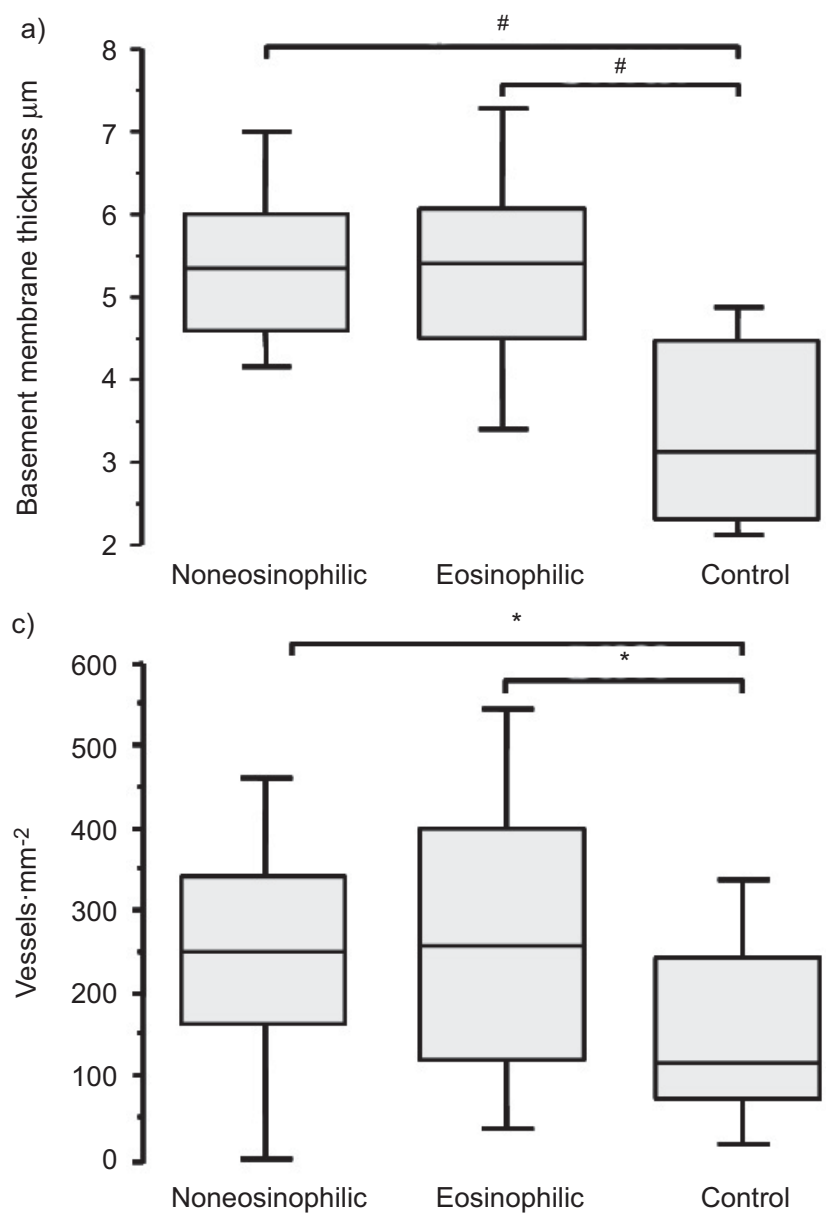

of subjects examined, but both eosinophilic and noneosinophilic asthmatics had a decreased expression of TGF- $\beta$ receptor type II compared with controls (48 (0-829) cells $\cdot \mathrm{mm}^{-2}$ and 19 $(0-451)$ cells $\cdot \mathrm{mm}^{-2}$, respectively, versus $160(0-1,048)$ cells $\cdot \mathrm{mm}^{-2}$ for controls; $\mathrm{p}<0.05$ for both versus controls) (fig. 5).

No significant differences were observed among the three groups of children for CD4-positive T-lymphocytes, neutrophils and mast cells, while there was a trend for macrophages to be increased, particularly in children with eosinophilic asthma (table 2).

Since the threshold chosen to identify children with eosinophilic and noneosinophilic asthma was somewhat arbitrary, to validate our results, we decided to compare the two extreme subsets: i.e. asthmatic children within the highest quartile of eosinophils $\left(>140 \mathrm{cells} \cdot \mathrm{mm}^{-2}\right)$ and those within the lowest quartile $\left(<21 \mathrm{cells} \cdot \mathrm{mm}^{-2}\right)$. No significant differences were observed between asthmatic children in the highest quartile and those in the lowest quartile for basement membrane thickness (5.9 (3.5-11.5) $\mu \mathrm{m}$ versus $5.4(3.8-8.6) \mu \mathrm{m})$, epithelial loss $(63(18-100) \%$ versus $50(20-94) \%)$, vessels (300 (9-620) vessels $\cdot \mathrm{mm}^{-2}$ versus $250(0-493)$ vessels $\left.\cdot \mathrm{mm}^{-2}\right)$, IL-4-positive cells (208 (0-676) cells $\cdot \mathrm{mm}^{-2}$ versus $101(56-451)$ cells $\left.\cdot \mathrm{mm}^{-2}\right)$, IL-5-positive cells (303 (0-810) cells $\cdot \mathrm{mm}^{-2}$ versus $323(0-920)$ cells $\left.\cdot \mathrm{mm}^{-2}\right)$ and TGF- $\beta$ receptor type II (47 (0-829) cells $\cdot \mathrm{mm}^{-2}$ and $19(0-451)$ cells $\left.\cdot \mathrm{mm}^{-2}\right)$. Importantly, versus control children,

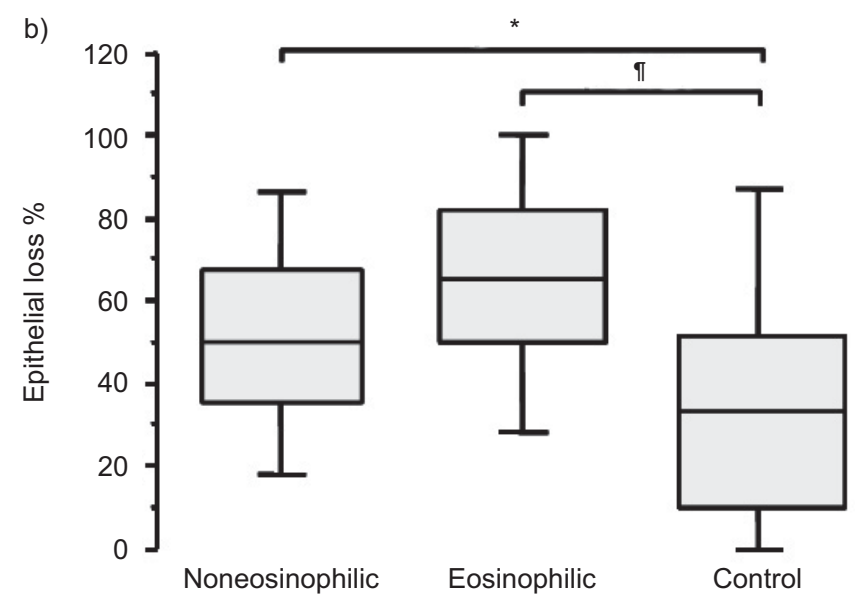

FIGURE 2. Individual values for a) basement membrane thickness, b) epithelial loss and c) vessels in children with noneosinophilic asthma, children with eosinophilic asthma and control children. The bottom and top of the boxes denote the 25th and 75th percentiles, respectively, the solid line is the median and the brackets are the 10th and 90th percentiles. p-values shown were calculated using the Mann-Whitney U-test; Kruskal-Wallis test $p$-values were: a) $p<0.0001$; b) $p=0.001$; and c) $p<0.05$. ${ }^{*}: p<0.0001$; $: p<0.005$; *: $p<0.05$.

all the pathological features were present not only in asthmatic subjects in the highest quartile of eosinophils, but also in those in the lowest quartile (except for IL-5-positive cells, which did not reach levels of statistical significance).

Interestingly, in our study, levels of circulating eosinophils paralleled those in bronchial biopsies in the two groups of subjects. In particular, it is worthwhile to note that, among 21 patients considered noneosinophilic based on tissue analysis, none had peripheral eosinophilia (eosinophil counts in peripheral blood $>450 \mathrm{~mm}^{-3}$ ). Conversely, among 34 patients considered to be eosinophilic based on tissue analysis, 14 also had peripheral eosinophilia, while 20 did not. These results indicate that when blood eosinophilia is present, then tissue eosinophilia is to be expected, but low levels of blood eosinophils do not exclude airway eosinophilia. Finally, when we compared subjects with concordant tissue/blood eosinophilia versus discordant tissue/blood eosinophilia, there were no pathological or clinical features able to differentiate the two subsets.

Since asthmatic children included in our study had a broad age range (2-15 yrs), to validate our findings in more homogeneous subgroups, we performed an age-stratified analysis, considering separately children aged $<6$ yrs $(n=49)$ or $\geqslant 6$ yrs $(n=31)$. There was no difference in any of the examined parameters (either structural or inflammatory) between asthmatic children of pre-school and school age (see online 

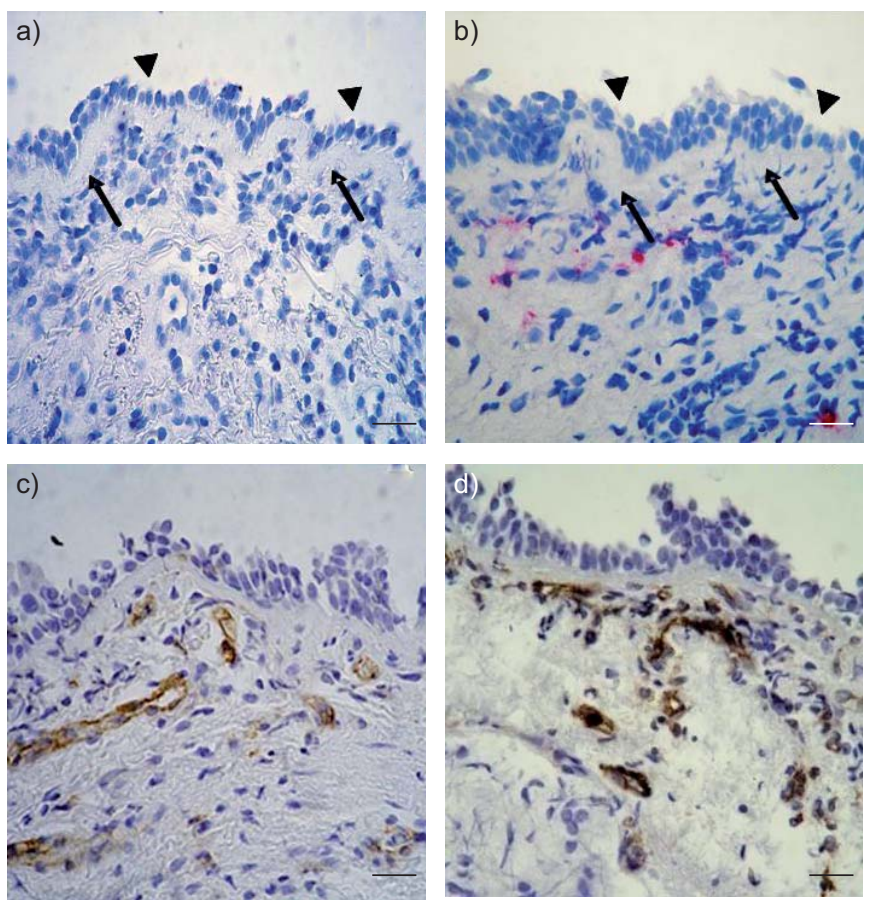

FIGURE 3. Bronchial biopsy sections from children with a, c) noneosinophilic asthma and b, d) eosinophilic asthma. a, b) Immunostaining with monoclonal antiEG2 antibody (eosinophils in red). c, d) Immunostaining with monoclonal anti-CD31 antibody (vessels in brown). Original magnification $\times 630$. Arrowheads: epithelial loss; arrows: reticular basement membrane thickening. Scale bars: $10 \mu \mathrm{m}$.

supplementary material). Moreover, in both age groups, structural and inflammatory parameters were increased in asthmatic children compared with controls, with no differences between the eosinophilic and noneosinophilic forms of the disease (tables 3 and 4). Compared with controls, all trends were confirmed numerically but some of the differences did not reach the levels of statistical significance, probably because of the low number of subjects in each subgroup.

Furthermore, to exclude the potential confounding effect of steroid therapy in some patients, we limited our analysis only to asthmatic children who were not being treated with inhaled corticosteroids $(n=36)$. The main results of our study were confirmed (online supplementary material, table E1). Indeed, even among untreated children, there were no differences in the results pertaining to epithelial loss, basement membrane thickening, angiogenesis or cytokine levels between children with eosinophilic and noneosinophilic asthma.

Since recurrent pneumonia was a frequent indication for bronchoscopy in our study, we performed a subanalysis considering only patients without recurrent pneumonia, and all the main messages were confirmed. Indeed, when we compared children with eosinophilic and noneosinophilic asthma in this population, there were no differences in the results pertaining to epithelial loss, basement membrane thickening or angiogenesis, nor to cytokine levels (online supplementary material, table E2).

Finally, we evaluated possible relationships between morphological and functional parameters characteristic of the disease. When all asthmatics were considered together, the number of eosinophils was not related to parameters of airway remodelling, but it correlated marginally with the number of macrophages $(r=0.28, p=0.04)$, with that of circulating eosinophils $(r=0.28, p=0.01)$, with the expression of $\mathrm{IL}-4$ $(r=0.29, p=0.004)$ and with FEV1/FVC ratio $(r=-0.39$, $p=0.03$ ). Neither epithelial loss, basement membrane thickening nor the number of vessels was related to FEV1/FVC, FVC, FEV1 or bronchodilator reversibility. This lack of correlation was a consistent finding whether we considered all asthmatic children as one group or as eosinophilic and noneosinophilic groups considered separately. Other weak correlations were observed, whose correlation coefficients never exceeded 0.5. a)

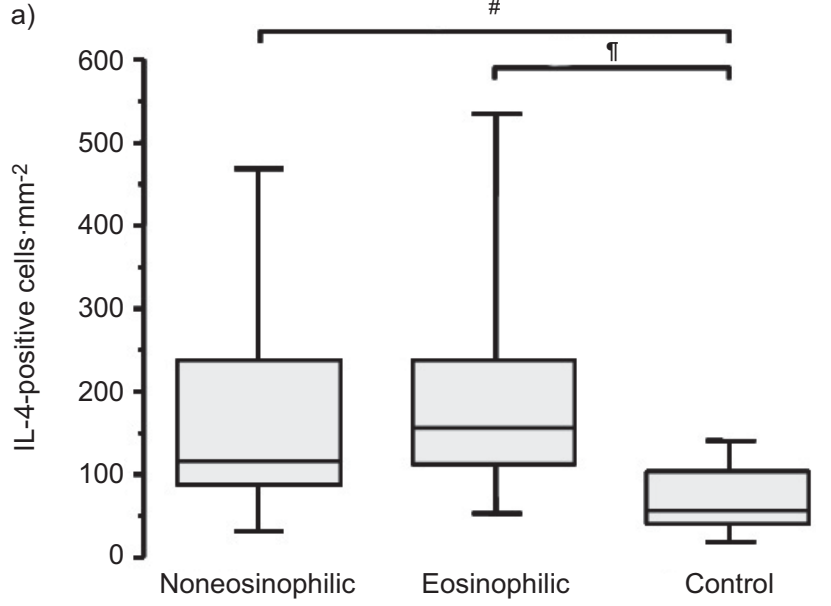

b)

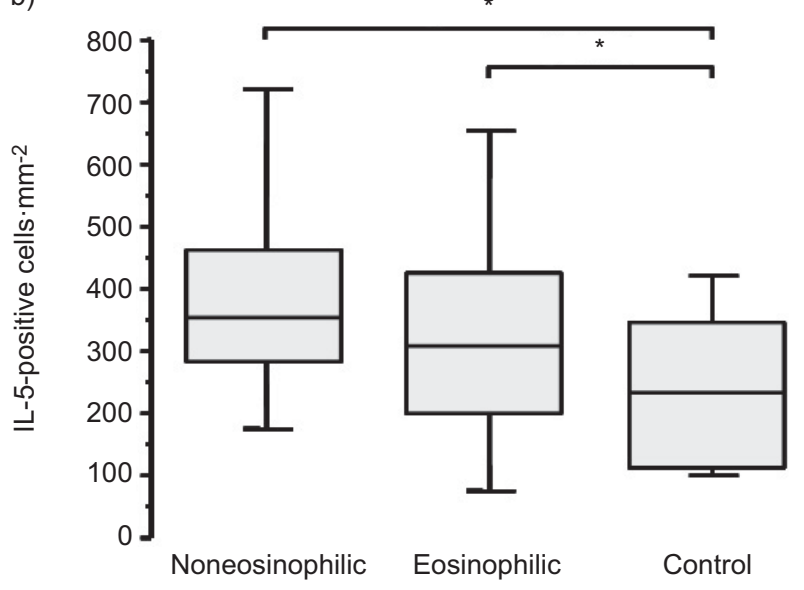

FIGURE 4. Individual values for a) interleukin (IL)-4-positive cells and b) IL-5-positive cells, in children with noneosinophilic asthma, children with eosinophilic asthma and control children. The bottom and top of the boxes denote the 25th and 75th percentiles, respectively, the solid line is the median and the brackets are the 10th and 90th percentiles. $p$-values shown were calculated using the Mann-Whitney U-test; Kruskal-Wallis test $p$-values were: a) $p=0.0001 ;$ and $b) p=0.002 .{ }^{*}: p=0.007 ;{ }^{~}: p<0.0001$; $*: p<0.05$ 
a)

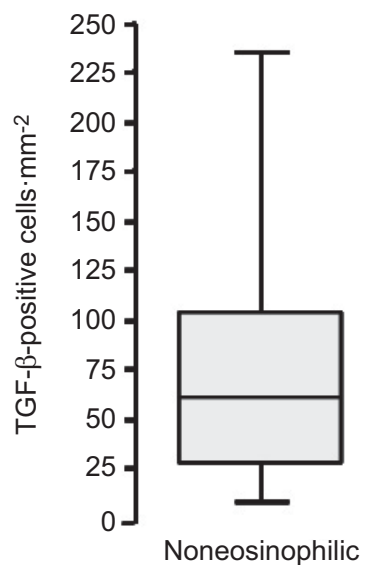

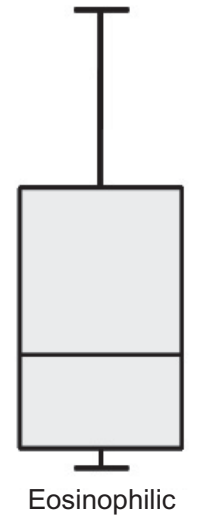

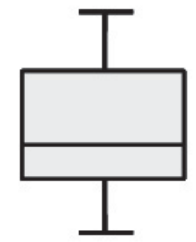

Control b)

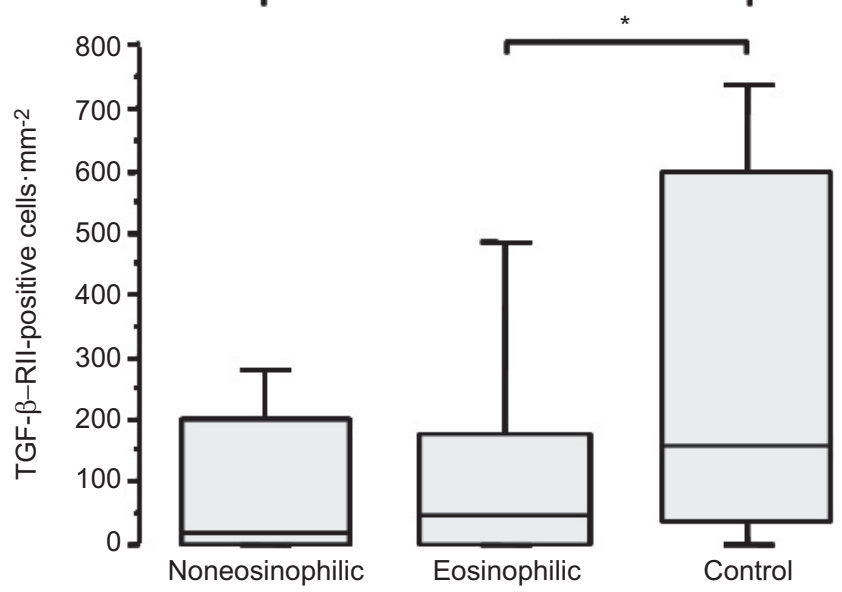

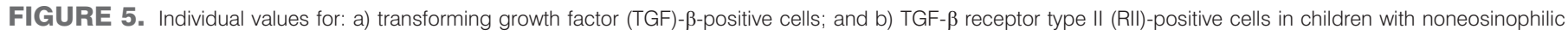

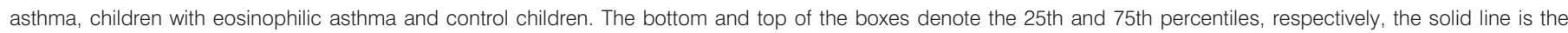

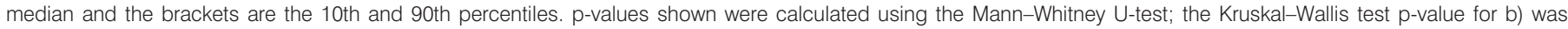
$p=0.05$. * $: p<0.05$

These are reported, for completeness, in the online supplementary material.

\section{DISCUSSION}

This study investigated, for the first time, airway remodelling in children with noneosinophilic asthma in comparison with the eosinophilic form of the disease, to elucidate the relationship between airway inflammatory and structural changes in the first years of life. Interestingly, it demonstrates that structural changes characteristic of asthma (basement membrane thickening, epithelial loss and angiogenesis) are present not only in children with eosinophilic, but also in those with noneosinophilic asthma. These results do not throw into question the importance of eosinophils as effector cells in asthma, but rather suggest that other pathways may be involved, thus highlighting the complexity of the disease.

Eosinophils have long been credited with a central role in asthma. Indeed, eosinophilia is a known risk factor for the development of respiratory symptoms, and, among asthmatics, it is associated with higher mortality risk, exacerbations and lung function impairment [19-22]. In particular, sputum eosinophilia is associated with lung function decline in asthmatic patients with persistent airflow limitation [23, 24] and, more importantly, eosinophilia is able to predict the subsequent development of persistent airway obstruction among adults with an early onset of symptoms [22]. Similarly, increased sputum and circulating eosinophils are associated with functional impairment even in children with asthma [25].

Based on these observations, it could be hypothesised that the relationship between eosinophils and impaired lung function could be mediated by an effect of these inflammatory cells on airway remodelling. Indeed, eosinophils have the potential to cause damage to the epithelium through the release of basic proteins, lipid mediators and reactive oxygen species. Moreover, they could contribute to remodelling of the airway wall through the release of mediators with fibrogenic activity $[26,27]$. However, in our study, structural changes were present in children with noneosinophilic asthma just as in those with eosinophilic disease, and eosinophilic inflammation was not related to any of the components of airway remodelling. These results suggest that the factors promoting airway remodelling are probably different from those controlling airway eosinophilia. Interestingly, not only structural changes, but even the expression of IL- 4 and IL-5 were not significantly different between children with eosinophilic and noneosinophilic asthma, indicating that persistence of eosinophils in the tissue

\section{TABLE 2 Cellular counts in the subepithelium}

\begin{tabular}{lcrr} 
& Eosinophilic & Noneosinophilic & Control \\
\hline Eosinophils cells $\cdot \mathbf{m m}^{-2}$ & $111(29-620)^{\#}$ & $13(0-28)^{\star}$ & $7(0-845)$ \\
CD4+ T-lymphocytes cells $\cdot \mathbf{m m}^{-2}$ & $308(0-1546)$ & $202(0-1423)$ & $244(0-1826)$ \\
Macrophages cells $\cdot \mathbf{m m}^{-2}$ & $113(0-597)$ & $85(0-430)$ & $56(8-732)$ \\
Neutrophils cells $\cdot \mathbf{m m}^{-2}$ & $116(0-1023)$ & $158(0-611)$ & $134(0-535)$ \\
Mast cells cells $\cdot \mathbf{m m}^{-2}$ & $86(0-755)$ & $129(12-575)$ & $56(6-676)$
\end{tabular}

Data are presented as median (range). ${ }^{*}: \mathrm{p}<0.0005$ versus children with non-eosinophilic asthma and versus control children; *: $p<0.05$ versus control children. 
TABLE 3 Subanalysis in children aged $<6$ yrs

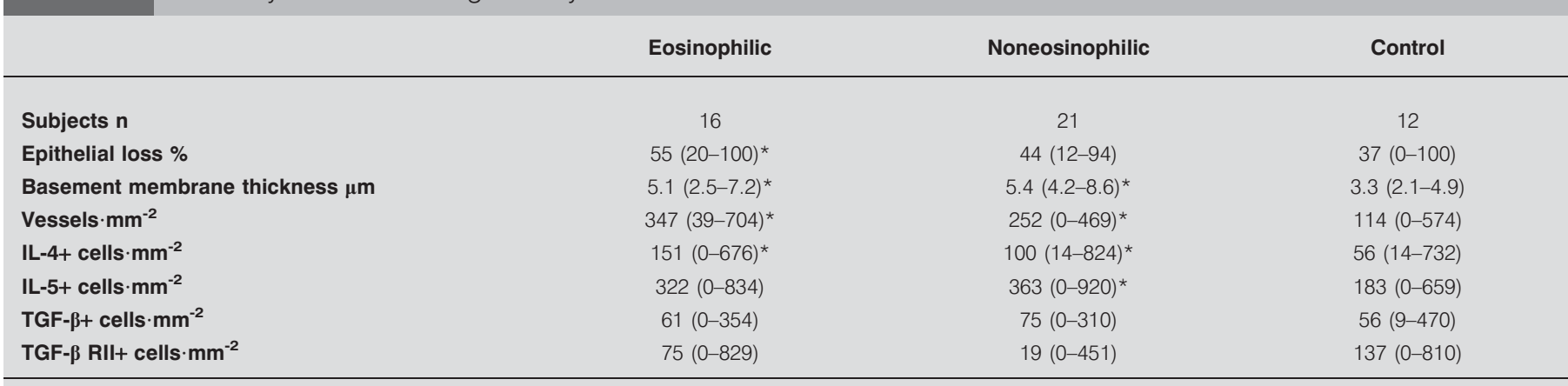

Data are presented as median (range), unless otherwise stated. IL: interleukin; TGF: transforming growth factor; RII: receptor type II. *: $p<0.05$ versus controls (MannWhitney U-test).

is a complex process that goes beyond the upregulation of these Th2 cytokines. It may appear surprising that the expression of IL-4, and particularly IL-5, was upregulated in children with noneosinophilic asthma; however, this is consistent with the idea that some patients never exhibit eosinophilia [28], even in the presence of a pro-eosinophilic milieu.

Indeed, the degree of variability in tissue eosinophil counts in our study was considerable: $\sim 60 \%$ of asthmatic children had eosinophils above the 90th percentile of controls, while $40 \%$ had values below this cut-off. These frequencies are in line with those reported in adults with asthma by studies using induced sputum [14-16], suggesting that the partition we used was indeed appropriate. We should acknowledge that the stability of the noneosinophilic phenotype could be questionable. A recent longitudinal study reported that this pattern was fairly stable [29], while others showed a higher degree of variability [30, 31]. Many potential factors could influence variability of cellular counts, with inhaled corticosteroid use and active smoking being the most prevalent [16]. Of note, the influence of smoking can be considered trivial in our study (no active, very low prevalence of second-hand smoking) and a minority of children were being treated with inhaled corticosteroids (only four out of 55 with high doses). Moreover, our results were confirmed even when we excluded treated children from the analysis and when we compared the two extreme subsets for eosinophil distribution, i.e. asthmatic children within the highest quartile to those in the lowest quartile. In fact, the degree of airway remodelling was really the same in asthmatic children with scant eosinophils and in those in whom eosinophilic infiltration was massive.

Overall, as suggested by other observations [32, 33], airway inflammation in asthma seems to be dissociated from functional and structural abnormalities just as in our study inflammation is dissociated from airway remodelling.

Our observations could be relevant in the context of clinical studies testing whether anti-inflammatory therapies would be able to modify the impairment of lung function. For instance, selective removal of eosinophils with a monoclonal antibody against IL-5, though reducing the rate of exacerbations and improving asthma control in patients with refractory eosinophilic asthma, had little effect on functional parameters [34, 35]. Similarly, steroid therapy does not affect lung function impairment in very young children [36,37], even if it seems to have a slight effect in adults with recent-onset asthma [38], suggesting that childhood asthma is probably different from adult asthma. On the same line, while we found that a thickened basement membrane was present even in children with noneosinophilic asthma, some studies in adults reported thickening only in patients with prominent eosinophilia [39, 40]. These

TABLE 4 Subanalysis in children $\geqslant 6$ yrs

\begin{tabular}{|c|c|c|c|}
\hline Subjects $n$ & 18 & 7 & 6 \\
\hline Basement membrane thickness $\mu \mathrm{m}$ & $6.0(3.7-11.5)^{*}$ & $4.6(3.8-6.7)^{\star}$ & $2.9(1.9-4.9)$ \\
\hline Vessels $\cdot \mathrm{mm}^{-2}$ & $231(9-620)$ & $245(0-493)$ & $146(0-576)$ \\
\hline IL-4+ cells $\cdot \mathrm{mm}^{-2}$ & $178(49-620)^{*}$ & $145(0-451)$ & $56(8-141)$ \\
\hline TGF- $\beta$ RII+ cells $\cdot \mathrm{mm}^{-2}$ & $46(0-216)$ & $34(0-293)$ & $441(0-1048)$ \\
\hline
\end{tabular}

Data are presented as median (range) unless otherwise stated. IL: interleukin; TGF: transforming growth factor; RII: receptor type II. *: $p<0.05$ versus controls (MannWhitney U-test). 
observations again support the concept that phenotypes in childhood asthma represent a different population than in adults. Indeed, the lack of eosinophils in adults with asthma has been associated with increased pulmonary neutrophilia [14-17] while, in our study, there was no evidence of neutrophilia in children with noneosinophilic asthma.

We are well aware that there are diagnostic issues in children, particularly in the youngest ones, because of the multifactorial nature of wheezing [41]. We were very careful when assessing the pattern of symptoms that were not purely virus-induced, but rather multi-trigger, and had to be responsive to bronchodilators. As recently pointed out [41], there is insufficient evidence in the literature on the pathophysiological mechanisms at pre-school age. It is therefore important to highlight that in our study the airway pathology characteristic of asthma was present in children aged $<6$ yrs just as in the oldest ones, and that airway remodelling occurred both in children with eosinophilic and those with noneosinophilic disease even at pre-school age. Of interest, when we examined TGF- $\beta$ signalling, which plays important regulatory roles in fetal and postnatal lung development, we observed a reduced expression of the type 2 receptor in both eosinophilic and noneosinophilic asthma. This observation confirms our previous findings in a different subset of children [7], but its significance remains to be clarified. Since TGF- $\beta$ signalling may affect the growth of both epithelium and smooth muscle, it is conceivable that alterations in this pathway may interfere with the growth of the lung structure.

There are potential criticisms of our study. We acknowledge that the majority of children underwent bronchoscopy for clinical indications other than asthma (otherwise biopsy sampling in children would not be feasible for ethical reasons), and the presence of concomitant diseases could have influenced the results. However, since these conditions were distributed equally among the three groups of subjects, we are confident that they did not affect the observed differences. Moreover, we should admit that a crucial component of airway remodelling, i.e. the increase in smooth muscle mass, has not been examined in our report. Because bronchial biopsies sample only a small portion of the bronchial wall, analysis of smooth muscle is not always possible and this is particularly true in children because biopsies are quite small. Lack of more refined functional parameters, such as forced oscillatory resistance or specific airway conductance, which could detect subtle changes in upper airway resistance, is also a significant weakness of the present study [42]. Finally, children with noneosinophilic asthma were not completely devoid of eosinophils, having values marginally higher than controls. However it seems unlikely that the remodelling observed in these subjects was caused by these scanty eosinophils, since all components of airway remodelling were present even in children within the lowest quartile (whose eosinophil values were similar to controls). We should admit that our study gives only a static picture of the inflammation present in airway tissue at a specific time point, and therefore we cannot draw conclusions on the stability of the phenotypes, in particular in relation to exacerbation or remission of symptoms. Noninvasive markers can be evaluated longitudinally; however, analysis of airway biopsies, with all its limitations, gives us the unique opportunity to evaluate the inflammatory pattern exactly in the airway tissue, where structural changes occur.

In conclusion, this study demonstrates that, even among children, a considerable proportion of asthmatics do not have evidence of tissue eosinophilia. Interestingly, the typical airway remodelling is present in children with noneosinophilic asthma just as in those with the eosinophilic form of the disease. These results suggest that structural changes develop early in the airways of children with asthma, and eosinophilic inflammation is not a necessary requirement.

\section{SUPPORT STATEMENT}

The present study was funded by the University of Padua, Italian Ministry of Universities and Research and the Italian Society for Paediatric Respiratory Diseases (SIMRI).

\section{STATEMENT OF INTEREST}

A statement of interest for M. Saetta can be found at www.erj. ersjournals.com/site/misc/statements.xhtml

\section{ACKNOWLEDGEMENTS}

The authors thank C.A. Drace (University of Padua, Padua, Italy) for assistance in editing the manuscript.

\section{REFERENCES}

1 Global Initiative for Asthma. Global strategy for asthma management and prevention www.ginasthma.org/download.asp?intId=430 Date last updated: December 2009.

2 Carlsen KH, Hedlin G, Bush A. Childhood asthma in the year of the lung. Eur Respir J 2010; 36: 6-7.

3 Spycher BD, Silverman M, Brooke AM, et al. Distinguishing phenotypes of childhood wheeze and cough using latent class analysis. Eur Respir J 2008; 31: 974-981.

4 Scott M, Kurukulaaratchy RJ, Raza A, et al. Understanding the nature and outcome of childhood wheezing. Eur Respir J 2009; 33: 700-701.

5 Matricardi PM, Illi S, Keil T, et al. Predicting persistence of wheezing: one algorithm does not fit all. Eur Respir J 2010; 35: 701-703.

6 Lloyd CM, Hessel EM. Functions of T cells in asthma: more than just Th2 cells. Nature Rev Immunol 2010; 10: 838-848.

7 Barbato A, Turato G, Baraldo S, et al. Airway inflammation in childhood asthma. Am J Respir Crit Care Med 2003; 168: 798-803.

8 Barbato A, Turato G, Baraldo S, et al. Epithelial damage and angiogenesis in the airway of children with asthma. Am J Respir Crit Care Med 2006; 174: 975-981.

9 Saglani S, Payne DN, Zhu J, et al. Early detection of airway wall remodeling and eosinophilic inflammation in preschool wheezers. Am J Respir Crit Care Med 2007; 176: 858-864.

10 Turato G, Barbato A, Baraldo S, et al. Nonatopic children with multitrigger wheezing have airway pathology comparable to atopic asthma. Am J Respir Crit Care Med 2008; 178: 476-482.

11 Saglani S, Mathie SA, Gregory LG, et al. Pathophysiological features of asthma develop in parallel in house dust mite-exposed neonatal mice. Am J Respir Cell Mol Biol 2009; 41: 281-288.

12 Lee JJ, Dimina D, Macias MP, et al. Defining a link with asthma in mice congenitally deficient in eosinophils. Science 2004; 305: 1773-1776.

13 Humbles AA, Lloyd CM, McMillan SJ, et al. A critical role for eosinophils in allergic airways remodeling. Science 2004; 305: 1776-1779.

14 Douwes J, Gibson P, Pekkanen J, et al. Non-eosinophilic asthma: importance and possible mechanisms. Thorax 2002; 57: 643-648.

15 Green RH, Brightling CE, Woltmann G, et al. Analysis of induced sputum in adults with asthma: identification of subgroup with isolated sputum neutrophilia and poor response to inhaled corticosteroids. Thorax 2002; 57: 875-879. 
16 Cowan DC, Cowan JO, Palmay R, et al. Effects of steroid therapy on inflammatory cell subtypes in asthma. Thorax 2010; 65: 384-390.

17 Wenzel SE, Szefler SJ, Leung DY, et al. Bronchoscopic evaluation of severe asthma. Persistent inflammation associated with high dose glucocorticoids. Am J Respir Crit Care Med 1997; 156: 737-743.

18 Midulla F, de Blic J, Barbato A, et al. Flexible endoscopy of paediatric airways. Eur Respir J 2003; 22: 698-708.

19 Jansen DF, Schouten JP, Vonk JM, et al. Smoking and airway hyperresponsiveness especially in the presence of blood eosinophilia increase the risk to develop respiratory symptoms: 25-year follow-up study in the general adult population. Am J Respir Crit Care Med 1999; 160: 259-264.

20 Hospers JJ, Schouten JP, Weiss ST, et al. Asthma attacks with eosinophilia predict mortality from chronic obstructive pulmonary disease in a general population sample. Am J Respir Crit Care Med 1999; 160: 1869-1874.

21 Green RH, Brightling CE, McKenna S, et al. Asthma exacerbations and sputum eosinophil counts: a randomised controlled trial. Lancet 2002; 360: 1715-1721.

22 Guerra S, Sherrill DL, Kurzius-Spencer M, et al. The course of persistent airflow limitation in subjects with and without asthma. Respir Med 2008; 102: 1473-1482.

23 Contoli M, Baraldo S, Marku B, et al. Fixed airflow obstruction due to asthma or chronic obstructive pulmonary disease: 5-year follow-up. J Allergy Clin Immunol 2010; 125: 830-837.

24 Ten Brinke A, Zwinderman AH, Sterk PJ, et al. Factors associated with persistent airflow limitation in severe asthma. Am J Respir Crit Care Med 2001; 164: 744-748.

25 Covar RA, Spahn JD, Murphy JR, et al. Progression of asthma measured by lung function in the childhood asthma management program. Am J Respir Crit Care Med 2004; 170: 234-241.

26 Minshall EM, Leung DY, Martin RJ, et al. Eosinophil-associated TGF- $\beta_{1}$ mRNA expression and airways fibrosis in bronchial asthma. Am J Respir Cell Mol Biol 1997; 17: 326-333.

27 Hoshino M, Nakamura Y, Sim J, et al. Bronchial subepithelial fibrosis and expression of matrix metalloproteinase-9 in asthmatic airway inflammation. J Allergy Clin Immunol 1998; 102: 783-788.

28 Anderson GP. Endotyping asthma: new insights into key pathogenic mechanisms in a complex, heterogeneous disease. Lancet 2008; 372: 1107-1119.

29 van Veen IH, Ten Brinke A, Gauw SA, et al. Consistency of sputum eosinophilia in difficult-to-treat asthma: a 5-year follow-up study. J Allergy Clin Immunol 2009; 124: 615-617.
30 Pavord ID, Jeffery PK, Qiu Y, et al. Airway inflammation in patients with asthma with high-fixed or low-fixed plus as-needed budesonide/formoterol. J Allergy Clin Immunol 2009; 123: 10831089.

31 Al-Samri MT, Benedetti A, Prefontaine D, et al. Variability of sputum inflammatory cells in asthmatic patients receiving corticosteroid therapy. A prospective study using multiple samples. J Allergy Clin Immunol 2010; 125: 1161-1163.

32 Murray CS, Woodcock A, Langley SJ, et al. Secondary prevention of asthma by the use of Inhaled Fluticasone propionate in Wheezy Infants (IFWIN): double-blind, randomised, controlled study. Lancet 2006; 368: 754-762

33 Payne DN, Rogers AV, Adelroth E, et al. Early thickening of the reticular basement membrane in children with difficult asthma Am J Respir Crit Care Med 2003; 167: 78-82.

34 Haldar P, Brightling CE, Hargadon B, et al. Mepolizumab and exacerbations of refractory eosinophilic asthma. N Engl J Med 2009; 360: 973-984.

35 Nair P, Pizzichini MM, Kjarsgaard M, et al. Mepolizumab for prednisone-dependent asthma with sputum eosinophilia. $N$ Engl J Med 2009; 360: 985-993.

36 Guilbert TW, Morgan WJ, Zeiger RS, et al. Long-term inhaled corticosteroids in preschool children at high risk for asthma. N Engl J Med 2006; 354: 1985-1997.

37 Bisgaard H, Hermansen MN, Loland L, et al. Intermittent inhaled corticosteroids in infants with episodic wheezing. N Engl J Med 2006; 354: 1998-2005.

38 Pauwels R, Pedersen S, Busse W, et al. Early intervention with budesonide in mild persistent asthma: a randomized, double blind trial. Lancet 2003; 361: 1071-1076.

39 Berry M, Morgan A, Shaw DE, et al. Pathological features and inhaled corticosteroid response of eosinophilic and non-eosinophilic asthma. Thorax 2007; 62: 1043-1049.

40 Wenzel SE, Schwartz LB, Langmack EL, et al. Evidence that severe asthma can be divided pathologically into two inflammatory subtypes with distinct physiologic and clinical characteristics. Am J Respir Crit Care Med 1999; 160: 1001-1008.

41 Brand PL, Baraldi E, Bisgaard H, et al. Definition, assessment and treatment of wheezing disorders in preschool children: an evidence-based approach. Eur Respir J 2008; 32: 1096-1110.

42 Frey U, Merkus PJFM, eds. Paediatric Lung Function. Eur Respir Mon 2010; 47. 